THURSDAY, MAY 16,1878

\section{THE MICROPHONE}

WE were enabled to announce a fortnight ago, that Prof. Hughes, the inventor of the type-printing telegraphic apparatus which goes by his name, has made the wonderful discorery that certain bodies are sensitive to sound, in the same way as selenium is sensitive to light. That is to say, if we place these bodies in the circuit of a small battery, and subject them to soundvibrations, in other words, talk at them, the electric current continually passing through it will be so continuously modified by the voice that the object may be used instead of a telephone for sending a message.

Since our note was penned an opportunity has been aftorded us by the kindness of Prof. Hughes, of inquiring into the precise manner in which this and other startling results have been accomplished.

The impression left upon us by a careful following of all Mr. Hughes's experiments, is, that by them we are broiglit face to face with one of the most wonderful discoveries of the century. To see Prof. Huxley, who was one of those present, solemnly talking at a small glass tube about two inches long, was, in itself, a sight worth seeing; but to go into another part of the house, and, on putting a telephone to the ear to find that the talking at the glass tube there resulted in a quite perfect, very easily audible reproduction of the quality of every word which the Professor uttered, was a thing almost transcending the marrellous.

That by such experiments as these we are beginning to tap sources and modes of energy hitherto undreamt of was rendered most evident by an experiment which has suggested the name, placed at the head of this article, for the instrument by which it is accomplished. The deilicate rubbing. of a fine camel's hair pencil over a smooth wooden surface under certain conditions of contact, although, of course, inaudible in the ordinary way, was rendered evident in the telephone by a crackling noise, of which the intensity was almost painful to the ear. In this way Mr. Hughes has enabled Mr. Preece to hear a fly walk; we were not so fortunate as to hear this, because the only small $\mathrm{fly}$ available in the room, after having been carefully hunted down and inclosed in a small tumbler, obstinately declined to walk on the wood.

We have said so much by way of giving an idea in the first instance of the manner and result of the experimentation. The kind of inquiry into the molecular structure of bodies it renders possible, and the applications to which, undoubtedly, it will soon be put, will be best grasped after a somewhat detailed description of the apparatus itself.' This description was given by $\mathrm{Mr}$. Hughes at the meeting of the Royal Society held on Thurstay last, and it may safely be said that never was a more difficult problem presented to men of science by simpler apparatu:

Although a telephone, as will be seen, is part of the apparatus utilised, the total problem presented by Mr. Hughes is a very much more complex one than that presented by that most marvellous of inodern instruments.

Mr. Hughes has employed the telephone as a phonoVor.. xvirt, - No. 446 scope of the greatest delicacy, to detect variations in currents, and the consequent reproduction of sound. The materials experimented upon by him were arranged as in the following sketch, in which B represents a battery, $\mathrm{s}$ the source of sound or material examined, and $T$ the telephone or phonoscope:

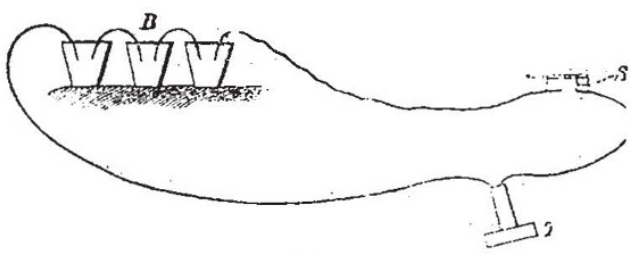

Fig. .

The battery was a simple Daniell's cell, of Minotto's form, made by using three common tumblers, a spiral piece of copper wire being placed at the bottom of each glass and covered with sulphate of copper, and the glass being then filled with well-moistened clay and water. A piece of zinc as the positive element was placed upon the clay. Insulated wires were attached to each plate, and three of these cells were joined in series.

All experiments werc made on a closed circuit.

Prof. Hughes's work was begun by studying the effect of strains, Sir WV. Thomson and others having shown that the resistance offered by wires to currents' is affected by them, it followed that as the conveyance of sound vibrations must induce variations in strains, the wire resistance should vary when it was used to convey sound.

A stretched wire was thercfore, in the first instance, introcluced at $\mathrm{S}$. The wire was talked at, but no effect was marked until a breaking strain was applied; at the moment of breaking, a sound was heard. Next, the broken ends were pressed together. The next stage in the experiments we quotc from the paper itself :-

"It was soun found that it was not at all necessary to join two wires endwise together to reproduce sound, but that any portion of an electric conductor would do so cven when fastencd to a board or to a table, and no matter how complicated the structure upon this board, or the materials used as a conductor, provided one or more portions of the electrical conductor were separated and only brought into contact by a slight but constant pressure. Thus, if the ends of the wire terminate in two common nails laid side by side, and are separated from each other by a slight space, were electrically connected by laying a similar nail between them, sound could be reproduced. The effect was improved by building up the nails log-hut fashion, into a square configuration, using ten or twenty nails. A piece of steel watch-chain acted well. Up to this point the sound or grosser vibrations were alone produced, the finer inflections. Were rnissing, or, in other words, the timbre of the voice was wanting, but in the following experiments the timbre became more and more perfect until it reached a perfection leaving nothing to be desired. I found that a metallic powder such as the white powder-a mixture of zinc and tin-sold in commerce as "white bronze," and fine metallic filings, introduced at the points of contact, oreatlv added to the perfection of the result."

Here, then, was articulate spesch clearly reproduced.

'rof. Hughes's next efforts were to discover the best material and form to give to his apparatus.

"Although I tried all forms of pressure and modes of contact, a lever, a spring, pressure in a glass tube sealed 
up while under the influence of strain, so as to maintain the pressure constant, all gave similar and invariable results, but the results varied with the materials used. All metals, however, could be made to produce identical results provided the division of the metal was small enough, and that the material used does not oxidise by contact with the air filtering through the mass. Thus platinum and mercury are very excellent and unvarying in their results, whilst lead soon becomes of such high resistance through oxidisation upon the surface, as to be of little or no use. A mass of bright round shot is peculiarly sensitive to sound whilst clean, but as the shot soon become coated with oxide this sensitiveness ceases. Carbon, again, from its surface being entirely free from oxidation, is excellent, but the best results I have been able to obtain at present have been from mercury in a finely divided state. I took a comparatively porous non-conductor, such as the willow charcoal used by artists for sketching, heating it gradually to a white heat and then suddenly plunging it in mercury. The vacua in the pores, caused by the sudden cooling, becone filled with innumerable minute globules of mercury, thus, as it were, holding the mercury in a fine state of division. I have also tried carbon treated in a similar manner with and without platinum deposited upon it from the chloricle of platinum. I have also found similar effects from the willow charcoal heated in an iron vessel to a white heat, and containing a free portion of tin, zinc, or other easily vaporised metal. Under such conditions the willow carbon will be found to be metallised, having the metal distributed throughout its pores in a fine state of division. Iron also seems to enter the pores if heated to a white heat without being chemically combined with the carbon as in graphite, and, indeed, some of the best results have been obtained from willow charcoal containing iron in a fine state of division.

"Pine charcoal treated in this manner (although a nonconductor as a simple charcoal) has high conductive powers, due to the iron; and from the minute division of the iron in the pores, is a most excellent material for the purpose."

The substances above referred to are in practice confined in a glass tube or box, and provided with wires to enable them to be easily inserted into a circuit. This is called a transmitter.

The resistance of the conductors employed is affected by sounds absolutely inaudible, and it is this quality which Prof. Hughes utilises in what he calls par excellence his microphone. This marvellous instrument, of which we shall hear so much in the future, consists of a lozengeshaped piece of gas-carbon one inch long, $\frac{1}{4}$ inch wide at its centre, and $\frac{1}{8}$ of an inch thick; the lower pointed end pirots upon a similar block, the upper rounded end plays free in another carbon block; all these pieces of carbon are tempered in mercury, and carbon is used in preference to any other material, as its surface does not oxidise. Prof. Hughes, in his paper, states :-

"The best form and materials for this instrument, however, have not yet been fully experimented on. Still, in its present shape, it is capable of detecting very faint sounds made in its presence. If a pin, for instance, be laid upon or taken off a table, a distinct sound is emitted, or, if a fly be confined under a table-glass, we can hear the fly walking, with a peculiar tramp of its own. The beating of a pulse, the tick of a watch, the tramp of a fly, can thus be heard at least a hundred miles distant from the source of sound. In fact, when further developed by study, we may fairly look for it to do for us, with regard to faint sounds, what the microscope does with matter too small for human vision."
The construction of the tube-transmitter exhibited to the Royal Society will be seen from the annexed woodcut. It consists of an exterior glass tube, $\mathrm{G}$, two inches long and $\frac{1}{4}$ inch in diameter; in it are four separate pieces of willow charcoal. A is made to press on $\mathrm{B}, \mathrm{C}$, $\mathrm{D}, \mathrm{E}$, and $\mathrm{F}$, until the resistance offered to the current is about one-third that of the line on which it is to be employed.

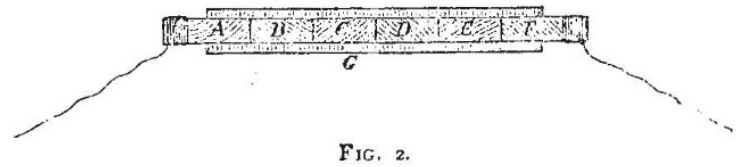

As Prof. Hughes properly remarks, it is as yet impossible to say what effect will flow from this wonderful cliscovery, a discovery which shows that it is possible to transmit clear and intelligent articulate speech, and to render the inaudible audible by the mere impact of sound waves upon matter along which an electric current is flowing.

It is not too early, however, to see that we have in the microphone a new method of attaching and quantifying molecular motions.

\section{PHYSICAL SCIENCE FOR ARTISTS ${ }^{1}$}

II.

THE examples I gave in my last paper were tested by a reference to the probable action of the aqueous vapour of our atmosphere in absorbing the various constituents of sunlight-the sun being the great source of light with which artists are specially concerned.

The reason that such a test was not applied long ago was because we are only just now beginning to understand why it is that the sun shines; why its light is white, and again why it is that this white light in passing through a great thickness of our atmosphere as it must do at sunrise and sunset-when the beams graze the surface of the earth instead of impinging upon it at a high angle-is in great measure absorbed or used up before it gets to the eye. The result of the condition to which $I$ have just referred is familiar to all; at sunrise and sunset the sun is red and not white.

The light of the sun we know now is due to the quivering or vibration of the molecules of the matter of which the sun is composed. No molecular vibration no light; given molecular vibration, the more intense it is the more intense is the light produced. The absorption of the sunlight by our air in the manner I have stated is due to the molecules of our air already in vibration being set in still stronger vibration by the sunlight passing through them. Here again then we have molecules and vibrations. In short the vibration of molecules, so far as light is given out or refiected or quenched by them, sharply defines the physical region in which artists are chiefly interested.

In a work which recently appeared, ${ }^{2}$ I have tried to show how the actions involved in sending a telegraphic message may help us to form a mental image of what goes on before the sensation of light is produced; we have a sending instrument, a medium, and a receiving instrument.

\footnotetext{
"Continued fr.m F. 3x.
2 "Stmles in Spectritm Analysis."
} 